\title{
Probable Adverse Event Relationship to Product or Procedure
}

National Cancer Institute

\section{Source}

National Cancer Institute. Probable Adverse Event Relationship to Product or Procedure.

NCl Thesaurus. Code C41357.

Probable adverse event relationship to study product or procedure is defined when there is a clear-cut temporal association between product or procedure administration and adverse event, and a potential alternative etiology of the event is not apparent. 